\title{
Selective Effect of Alcohol on Cellular Immune Responses of Lymphocytes From AIDS Patients
}

\author{
MADHAVAN P. N. NAIR,*1 NIRANJAN M. KUMAR,* ZIAD A. KRONFOL, $\dagger$ \\ LOUIS A. SARAVOLATZ, $\ddagger$ RAVEENDRAN POTTATHIL, $\S$ JOHN F. GREDEN $\dagger$ \\ AND STANLEY A. SCHWARTZ* \\ *The State University of New York at Buffalo, Department of Medicine \\ $\dagger$ Departments of Psychiatry and Alcohol Research Center, The University of Michigan, Ann Arbor \\ $\ddagger$ Henry Ford Hospital, Detroit \\ $\S$ Speciality Laboratories Inc., San Diego
}

\begin{abstract}
NAIR, M. P. N., N. M. KUMAR, Z. A. KRONFOL, L. A. SARAVOLATZ, R. POTTATHIL, J. F. GREDEN AND S. A. SCHWARTZ. Selective effect of alcohol on cellular immune responses of lymphocytes from AIDS patients. ALCOHOL 11(2) 85-90, 1994. - In this study we examined the in vitro effects of alcohol on the proliferative responses of lymphocytes from healthy donors and AIDS patients to a recombinant fusion peptide, env-gag, corresponding to portions of the gp 41 envelope (env) and internal core (gag) proteins of HIV. The effects of alcohol (ETOH) on the natural killer (NK) cell activities of lymphocytes from healthy donors and patients with AIDS were also investigated. Peripheral blood mononuclear cells from both normal donors and AIDS patients produced significant levels of lymphocyte proliferative responses to the HIV env-gag peptide; however, these responses were significantly higher in patients with AIDS, showing the specificity of the response. The env-gag-induced proliferative responses of lymphocytes from normal subjects were significantly suppressed when cultures contained only higher levels of ETOH $(0.2 \%$ and $0.3 \%)$, whereas ETOH even at a lower level $(0.1 \%)$ produced significant suppression of the env-gag-induced proliferation of lymphocytes only from AIDS patients. Direct addition of ETOH at concentrations of $0.1 \%, 0.2 \%$, and $0.3 \%$ to cultures of lymphocytes from normal donors and NK target cells did not produce significant suppression of NK cell activities. However, ETOH at concentrations of $0.2 \%$ and $0.3 \%$ significantly suppressed the NK activities of lymphocytes from AIDS patients, and the suppressive effect was observed at all E:T cell ratios examined. Control peptide from the Escherichia coli expression vector did not produce any significant effect on lymphocyte proliferative responses or NK activity of both normal donors and AIDS patients. ETOH at various concentrations $(0.1 \%, 0.2 \%$, and $0.3 \%)$ or env-gag $(10 \mathrm{ng} / \mathrm{ml})$, when individually added to cultures of NK effector and target cells and allowed to remain throughout the 4-h assay period, produced no significant suppression of the NK activity of normal lymphocytes. This suggests a selective inhibitory effect of ETOH on lymphocyte proliferative responses and NK activity of lymphocytes from AIDS patients. Thus ETOH at intoxicating levels may have immunomodulatory effects on the host's immune responses to HIV infection.
\end{abstract}

Alcohol Human immunodeficiency virus peptides Lymphocyte proliferation Natural killer cells Acquired immunodeficiency disease syndromes

PREVIOUS studies have shown that chronic alcohol consumption is associated with abnormalities of humoral $(5,8-$ $10,21,22)$ and cellular immunity $(6,11,13,14,39)$, including dysfunction of suppressor $(11,12,15,40,41)$, helper $(18)$, and cytotoxic lymphocyte activities $(1,7,19,20,33,36)$ and production of soluble immune mediators (31). We have recently reported that lymphocytes from nonalcoholic, healthy donors precultured in vitro with different concentrations of alcohol manifest decreased levels of natural killer (NK), antibody-dependent cellular cytotoxic (ADCC), and lymphokine-activated killer (LAK) cell activities (23).

Infection by the human immunodeficiency virus (HIV) causes profound dysfunction of cellular and humoral immune responses (32). It has been reported that many people who are exposed to or infected with HIV do not necessarily manifest rapid disease progression to frank AIDS (4), suggesting that,

\footnotetext{
' Requests for reprints should be addressed to Madhavan P. N. Nair, Ph.D., Buffalo General Hospital, Department of Medicine, 100 High Street, Buffalo, NY 14203.
} 
in addition to the etiologic agent HIV-1, cofactors may exist which affect the disease progression. Thus it has been hypothesized that repeated exposure to HIV, malnutrition, coincident infections, and use of recreational drugs such as heroin, marijuana, cocaine, alcohol, and so on, alone or in combination, may increase the susceptibility of the host to HIV infection. The effect of alcohol alone or circulating HIV peptides on the immune response of the host to HIV infection and in the subsequent development of AIDS is not well understood. This investigation examines the direct effect of alcohol on NK activities and specific proliferative responses of lymphocytes from AIDS patients in comparison with age- and sex-matched normal controls.

MATERIALS AND METHODS

\section{Recombinant HIV env-gag Peptide}

The expression and purification of recombinant HIV peptides in $E$. coli have been described earlier $(8,21,34)$. Env-gag is a recombinant fusion product that contains an 80 -aminoacid sequence from the gp 41 surface glycoprotein of HIV and a 190-amino-acid sequence from the HIV internal core protein, p $24(5,29)$.

\section{Normal Donors and AIDS Patients}

Male AIDS patients (CDC group IV) (4) without Kaposi's sarcoma and ranging in age from 29 to 41 years were recruited from the Infectious Diseases Clinic of Henry Ford Hospital, Detroit. HIV status was determined by enzyme-linked immunosorbent blocking assay (ELISA) and Western blot assays. The patients and control subjects were age and sex matched and were not consuming alcohol or any other drugs of abuse at the time of the study. Donors were apprised of this study and consents were obtained consistent with the policies of the appropriate institution and the National Institutes of Health.

\section{Isolation of Peripheral Blood Mononuclear Cells}

Peripheral blood from healthy (HIV negative), nonalcoholic individuals and AIDS patients was drawn into a syringe containing heparin ( 20 units $/ \mathrm{ml}$ ). Peripheral blood mononuclear cells (PBMCs) were isolated from heparinized venous blood using a modified method of Boyum (3). Blood was diluted with an equal volume of normal saline and was centrifuged at $400 \times g$ for $30 \mathrm{~min}$ at $18^{\circ} \mathrm{C}$. The mononuclear cell band was harvested, washed three times with saline, and resuspended in RPMI 1640 medium containing $25 \mathrm{mM} \mathrm{N}$-(2hydroxyethyl)piperazine- $N^{\prime}$-2-ethanesulfonic acid (HEPES) buffer supplemented with $10 \%$ heat-inactivated fetal calf serum (GIBCO), $80 \mu \mathrm{g}$ gentamicin $/ \mathrm{ml}$ (Schering, Kenilworth, $\mathrm{NJ}$ ), and $300 \mu \mathrm{g}$ fresh glutamine/ml (complete medium).

\section{Lymphocyte Proliferation Assay}

This assay was performed as described (24). Briefly, 2 $\times 10^{5}$ PBMCs were cultured in complete medium in sterile U-bottom microtitration plates (Dynatech, Alexandria, VA). Specific cultures received recombinant HIV env-gag peptide at concentrations of $0,1,5,10$, and $50 \mathrm{ng} / \mathrm{ml}$. ETOH USP, absolute $20 \hat{0}$ proof, diluted in Hanks balanced salt solution (HBSS) was added to the cultures to yield final concentrations of $0.1 \%, 0.2 \%$, and $0.3 \%(\mathrm{v} / \mathrm{v})$. ETOH was added directly to the PBMCs containing HIV peptides at the beginning of the culture period, and the cells were incubated for $72 \mathrm{~h}$ at $37^{\circ} \mathrm{C}$ in a $5 \% \mathrm{CO}_{2}$ /air incubator. Control cultures containing either
ETOH, HIV peptides, or media alone were concomitantly set up. $\left[{ }^{3} \mathrm{H}\right]$ Thymidine $(1 \mu \mathrm{ci} ; 1 \mathrm{Ci}=37 \mathrm{GBq})$ was added to each well during the last $24 \mathrm{~h}$ of incubation. The cultures were collected by an automated cell harvester and incorporation of $\left[{ }^{3} \mathrm{H}\right]$ thymidine into lymphocyte DNA was determined with a scintillation counter. Results are expressed as cpm per $2 \times$ $10^{5}$ cells.

\section{Preparation of Effector Cells for NK Assay}

PBMCs in RPMI 1640 with $10 \%$ fetal calf serum were depleted of adherent cells by passage through a 7-ml column of Sephadex G-10 beads (Pharmacia Fine Chemicals, Piscataway, NJ). After $45 \mathrm{~min}$ of incubation at $37^{\circ} \mathrm{C}$, nonadherent peripheral blood lymphocytes (PBLs) were washed through the column with medium at $37^{\circ} \mathrm{C}$. Cell recovery was $>70 \%$ of the total input, and monocyte contamination as indicated by nonspecific esterase staining was $<2 \%$.

\section{Tumor Target Cells}

The human erythroleukemia cell line, K562, was used as a target for NK cells. Passaged, 48-h-old target cells were washed twice with complete medium. Two $0.8-\mathrm{ml}$ aliquots of complete medium containing $5 \times 10^{6}$ tumor cells, $200 \mu \mathrm{Ci}$ of ${ }^{51} \mathrm{Cr}$ as sodium chromate (New England Nuclear, Boston), were added. The cells were incubated at $37^{\circ} \mathrm{C}$ for $1 \mathrm{~h}$ in a humidified atmosphere of $5 \% \mathrm{CO}_{2}$ in air with intermittent shaking. After incubation, the cells were washed three times with complete medium and resuspended to a concentration of $2 \times 10^{5}$ cells $/ \mathrm{ml}$.

\section{Assay for NK Activity}

NK activity was determined in a direct ${ }^{51} \mathrm{Cr}$-release assay as described (23). Briefly, varying concentrations of viable effector cells in complete medium were added to triplicate cultures of ${ }^{51} \mathrm{Cr}$-labeled target cells in $0.2-\mathrm{ml}$ volumes in $\mathrm{V}$ bottomed microtitration plates (Dynatech Labs, Alexandria, VA). After centrifugation at $40 \times g$ for 2 min the cells were incubated at $37^{\circ} \mathrm{C}$ in a humidified atmosphere of $5 \% \mathrm{CO}_{2}$ in air for $4 \mathrm{~h}$. Percent cytotoxicity was calculated as follows:

$$
\% \text { Cytotoxicity }=\frac{\text { Experimental Release }- \text { Spontaneous Release }}{\text { Total Release }- \text { Spontaneous Release }} \times 100,
$$

where total release represents counts obtained in an aliquot of $1 \times 10^{4}$ target cells and spontaneous release represents counts released into the medium in control wells containing only 1 $\times 10^{4}$ target cells. Spontaneous release of ${ }^{51} \mathrm{Cr}$ was always in the range of $2-5 \%$ of total labeling. Because the maximum releasable counts (total labeling) determined by either lysin! an aliquot of labeled target cells or using unlysed target cell: were the same, the latter method was employed to obtain tota release. ETOH at a final concentration of $0.1 \%, 0.2 \%$, o $0.3 \%$ was added directly to the reaction mixture of effecto and target cells and incubated for $4 \mathrm{~h}$ and the NK activity was measured. Control cultures containing media instead of ETOH were examined concomitantly.

\section{RESULTS}

Effect of ETOH on Proliferative Responses to HIV env-gag Peptides of Lymphocytes From Normal Donors and AIDS Patients

To investigate whether HIV env-gag peptide induces specific proliferative responses of lymphocytes from AIDS pa- 
tients, lymphocytes from these patients were cultured with $10-\mathrm{ng} / \mathrm{ml}$ concentrations of env-gag and their proliferative responses were determined in comparison with normal lymphocytes. Data presented in Table 1 demonstrate that lymphocytes from AIDS patients produced greater proliferative responses to env-gag antigen; the magnitude of the response was 26731 cpm by lymphocytes from AIDS patients compared to 19316 cpm produced by normal lymphocytes.

We further investigated whether ETOH could produce significant suppressive effects on HIV env-gag-induced lymphocyte proliferative responses (Table 1). To examine this possibility, lymphocytes were cultured with $10 \mathrm{ng} / \mathrm{ml}$ of HIV env-gag and ETOH $(0.1-0.3 \%)$ for $72 \mathrm{~h}$ and their proliferative responses were measured. Normal lymphocytes cultured with env-gag plus $0.1 \% \mathrm{ETOH}(\mathrm{v} / \mathrm{v})$ produced a marginal increase in the lymphocyte proliferative response $(21390 \mathrm{cpm}) \mathrm{com}$ pared to env-gag alone-induced lymphocyte proliferation (19 $316 \mathrm{cpm})$, although this effect was not statistically significant $(p<.25)$. However, ETOH at increasing concentrations of $0.2 \%$ and $0.3 \%$ produced a dose-dependent inhibitory effect on the proliferative responses of normal lymphocytes to envgag peptide $(12781 \mathrm{cpm}, p<.05$ and $9131 \mathrm{cpm}, p<.01)$. Lymphocytes from AIDS subjects cultured with env-gag peptide also showed a significant proliferative response of 26 $731 \mathrm{cpm}$ compared to untreated cultures $(2832 \mathrm{cpm})$, and this response of AIDS patients' lymphocytes was significantly inhibited by ETOH even at $0.1 \%$ concentration $(19671 \mathrm{cpm}$, $p<.05$ ). ETOH at increased concentrations of $0.2 \%$ and $0.3 \%$ also produced significant inhibitory effects on env-gaginduced lymphocyte proliferative responses $(13670 \mathrm{cpm}$, $p<.005$ and $12216, p<.0025$ ). Thus our results show that a concentration of ETOH as low as $0.1 \%$, which did not cause any significant effects on env-gag-induced proliferative responses of normal lymphocytes, did produce a significant inhibitory effect on env-gag-induced proliferative response of lymphocytes from AIDS patients. Lymphocytes from both normal subjects and AIDS patients did not manifest any responses to either control peptides (a peptide derived from the Escherichia coli $[E$. coli] expression vector [HIV I vector 279291] used to clone the env-gag recombinant fusion peptide) or ETOH alone at any concentrations (data not presented).

The observed decrease in lymphocyte proliferation mediated by ETOH was not due to any toxic effects, as ETOH- treated cells were as viable as untreated controls. Evaporation of ETOH from our cell cultures reduced its concentration by $38 \%$ after $24 \mathrm{~h}, 47 \%$ after $48 \mathrm{~h}$, and $59 \%$ after $72 \mathrm{~h}$ as quantitated by gas chromatography. For example, ETOH at initial concentrations of $0.1 \%, 0.2 \%$, and $0.3 \%$ became $0.06 \%$, $0.12 \%$, and $0.18 \%$, respectively, after $72 \mathrm{~h}$. These concentrations are comparable to levels obtained in vivo at different stages of intoxication. No attempt was made to maintain a constant level of ETOH throughout the culture period to mimic the in vivo situation where ETOH levels in body fluids tend to decrease with time. Thus the immunosuppressive effects of ETOH may occur at even lower levels than the starting concentrations.

\section{Effect of ETOH on the NK Activity of Lymphocytes From Normal Donors and AIDS Patients}

In view of the findings that alcoholics are more susceptible to various infections and malignancies than nonalcoholics (28), and since a potential relationship exists between AIDS and alcohol abuse $(17,35,37,38)$, we examined the direct effect of ETOH on the NK activity of lymphocytes from normal donors and AIDS patients.

Data presented in Table 2 demonstrate that direct addition of ETOH at $0.1 \%, 0.2 \%$, and $0.3 \%$ concentrations did not produce any significant effect on NK activity of normal lymphocytes, the percent cytotoxicities being 20,18 , and 19 compared to $23 \%$ cytotoxicity manifested by untreated control cultures at a 25:1 E:T cell ratio. Lymphocytes from AIDS patients demonstrated a decreased level of cytotoxicity $(11 \%)$ compared to that of normal lymphocytes ( $23 \%$ cytotoxicity). However, direct addition of ETOH at concentrations of $0.1 \%, 0.2 \%$, and $0.3 \%$ produced a dose-dependent inhibition of the NK activity of AIDS patients' lymphocytes, the cytotoxicities being $8 \%(p<.05), 5 \%(p<.01)$, and $2 \%(p<$ $.002)$, respectively, compared to $11 \%$ cytotoxicity manifested by untreated lymphocytes.

Data presented in Table 3 demonstrate the effect of ETOH on the NK activity of lymphocytes from AIDS patients at different $E: T$ cell ratios. Lymphocytes from AIDS patients produced significantly lower NK activities at all E:T cell ratios, with cytotoxicities of $17 \%, 13 \%$, and $8 \%$, respectively, at 50:1, 25:1, and 12.5 E:T cell ratios. However, direct addi-

TABLE 1

EFFECT OF DIFFERENT CONCENTRATIONS OF ALCOHOL ON LYMPHOCYTE PROLIFERATION RESPONSE TO HIV env-gag BY NORMAL DONORS AND AIDS PATIENTS

\begin{tabular}{lcccc}
\hline \multicolumn{5}{c}{ Concentrations of ETOH $(\% \mathrm{v} / \mathrm{v})$} \\
\cline { 2 - 5 } & 0 & 0.1 & 0.2 & 0.3 \\
& \multirow{2}{*}{ Normal } & $(0.059)$ & $(0.118)$ & $(0.177)$ \\
& $19316 \pm 2810$ & $21390 \pm 1875$ & $12781 \pm 1937$ & $9131 \pm 1560$ \\
AIDS & & $p<.25$ & $p<.05$ & $p<.01$ \\
& $26731 \pm 3760$ & $19671 \pm 3700$ & $13670 \pm 2670$ & $12216 \pm 2917$ \\
& & $p<.05$ & $p<.005$ & $p<.0025$ \\
\hline
\end{tabular}

Two million peripheral blood mononuclear cells from $\mathrm{HIV}^{-}$and $\mathrm{HIV}^{+}$donors were cultured with HIV-I env-gag peptides $(10 \mathrm{ng} / \mathrm{ml})$ to which different concentrations of ETOH were added, and the proliferative responses of lymphocytes were determined. Results are means \pm SDs of four experiments using 10 normal and 10 AIDS subjects performed in triplicate. Statistical significance of differences in mean values was determined by Student's $t$ test. The concentration of ETOH in parenthesis is the level of ETOH present after $72 \mathrm{~h}$ of culture as measured by gas chromatography. 
TABLE 2

EFFECT OF DIRECT ADDITION OF ETOH ON THE NK ACTIVITY OF LYMPHOCYTES FROM NORMAL DONORS AND AIDS PATIENTS

\begin{tabular}{lcccc}
\hline \multirow{2}{*}{$\begin{array}{l}\text { Lymphocyte } \\
\text { Donors }\end{array}$} & \multicolumn{4}{c}{ Concentrations of ETOH $(\%)$} \\
\cline { 2 - 5 } & 0 & 0.1 & 0.2 & 0.3 \\
\hline Normals & $23.3 \pm 3.8$ & $20.8 \pm 3.0$ & $\begin{array}{c}18.9 \pm 2.8 \\
(p<.5)\end{array}$ & $\begin{array}{c}19.0 \pm 2.8 \\
(p<.5)\end{array}$ \\
AIDS & $11.9 \pm 2.0$ & $\begin{array}{c}8.6 \pm 0.5 \\
(p<.05)\end{array}$ & $\begin{array}{c}5.7 \pm 0.4 \\
(p<.01)\end{array}$ & $\begin{array}{c}2.8 \pm 0.6 \\
(p<.002)\end{array}$ \\
\hline
\end{tabular}

ETOH at concentrations of $0.1 \%, 0.2 \%$, and $0.3 \%$ was added directly to a mixture of effector and target cells that was incubated for $4 \mathrm{~h}$, and the natural killer cell activity was measured against K562 target cells. Values represent mean percent cytotoxicities \pm SDs of triplicate determinations from four experiments at 25:1 E:T cell ratios using a total of 10 different normals and 10 different AIDS subjects. Statistical significance of differences in the mean values was determined by a two-tailed Student's $t$ test.

tion of ETOH at concentrations of $0.2 \%$ produced significant inhibitory effects on their NK activities, the cytotoxicities being $10 \%(p<.05), 7 \%(p<0.02)$, and $3 \%(p<.005)$, respectively, for 50:1, 25:1, and 12.5:1 E:T cell ratios. These studies thus showed a specific inhibitory effect of ETOH on the activities of NK cells from AIDS patients at all E:T cell ratios, and such effects were not demonstrable with lymphocytes from normal subjects.

\section{DISCUSSION}

From these studies and others showing the inhibitory effects of ETOH on various functions of normal lymphocytes, as well as the clinically observed depressed immune status of alcoholic patients, it is reasonable to speculate that alcohol may compromise host immune responses against HIV infections. We recently reported that lymphocytes from normal donors exposed in vitro to recombinant HIV peptides show a dose-dependent induction of $\mathrm{IgG}$ production in vitro (24). However, HIV peptides also paradoxically suppressed pokeweed mitogen-induced IgG synthesis (24). We also reported that env-gag, a recombinant fusion product of env and gag sequences, could inhibit the NK activities of lymphocytes from AIDS patients (25). This is consistent with the suppressed NK activity seen in AIDS patients (30).

A number of investigations suggest a potential relationship between AIDS and alcohol abuse $(16,35,37)$. Recently it was demonstrated that moderate alcohol ingestion increased the in vitro susceptibility of normal peripheral blood mononuclear cells to infection with HIV (2). Another study showed a significantly higher rate of alcohol consumption among patients with more advanced HIV disease compared to asymptomatic HIV-infected individuals (16). Recent studies also showed that retroviral infections in the murine model also exacerbated the decreased host immune response to AIDS after retroviral infection $(26,40)$. Since such a potential association exists between alcohol and HIV susceptibility or disease progression $(16,26,27,35,37)$, it is possible that alcohol may compromise normal lymphocyte responses to HIV infection and may also have an inhibitory effect on the residual NK cell activities of lymphocytes from AIDS patients.

We report herein that addition of alcohol corresponding to intoxicating levels in vivo significantly suppresses lymphocyte proliferative responses to HIV antigens in both normal sub-

TABLE 3

EFFECT OF DIRECT ADDITION OF ETOH ON NK ACTIVITY OF LYMPHOCYTES FROM NORMAL DONORS AND AIDS PATIENTS AT DIFFERENT E:T CELL RATIOS

\begin{tabular}{llccc}
\hline & & \multicolumn{3}{c}{ E:T Cell Ratios } \\
\cline { 3 - 5 } Lymphocyte Donors & $50: 1$ & $25: 1$ & $12.5: 1$ \\
\hline \multirow{2}{*}{ Normals } & - ETOH & $37.2 \pm 5.0$ & $26.4 \pm 3.7$ & $20.0 \pm 2.9$ \\
& & $(p<.8)$ & $(p<.8)$ & $(p<.5)$ \\
\multirow{2}{*}{ AIDS } & +ETOH $(0.2 \% \mathrm{v} / \mathrm{v})$ & $35.0 \pm 4.9$ & $24.6 \pm 2.7$ & $18.7 \pm 3.1$ \\
& - ETOH & $17.2 \pm 2.1$ & $13.3 \pm 1.9$ & $8.7 \pm 1.8$ \\
& & $(p<.05)$ & $(p<.02)$ & $(p<.005)$ \\
& +ETOH $(0.2 \% \mathrm{v} / \mathrm{v})$ & $10.8 \pm 1.0$ & $7.0 \pm 0.9$ & $3.9 \pm 1.0$ \\
\hline
\end{tabular}

ETOH at a final concentration of $0.2 \%(\mathrm{v} / \mathrm{v})$ was added directly to a mixture of effector cells and target cells that was incubated for $4 \mathrm{~h}$, and the natural killer cell activity was measured against K562 target cells at different E:T cell ratios. Values represent mean percent cytotoxicities \pm SDs of triplicate determinations from four separate experiments using a total of 10 different normals and 10 different AIDS subjects. Statistical significance of differences in the mean values was determined by a two-tailed Student's $t$ test. 
jects and AIDS patients. It should be noted that ETOH at a lower concentration $(0.1 \%)$ significantly suppressed $(p<$ .05 ) the env-gag-induced lymphocyte proliferation in AIDS patients, while a similar concentration of alcohol did not produce any inhibitory effect on normal lymphocytes. Thus a selective inhibitory effect of ETOH was demonstrable on HIV antigen-induced proliferative responses of lymphocytes from AIDS patients. The mechanisms underlying the proliferative responses of normal lymphocytes from uninfected healthy donors to HIV peptides are not clearly understood.

Earlier we showed that HIV peptides also selectively suppressed the NK activities of lymphocytes from AIDS patients (25). In the present investigations, direct addition of ETOH to mixtures of effector cells from normal donors and target cells did not produce any significant suppression of NK activity, whereas significant suppression of NK activity was observed when intoxicating levels of ETOH were added directly to the mixture of effector lymphocytes from AIDS patients and targets. This demonstrates that lymphocytes from AIDS patients may be more susceptible to the suppressive effects of ETOH, compared to normal lymphocytes. Increased susceptibility of lymphocytes to these effects of ETOH may be one of several mechanisms of depressed NK cell functions seen in AIDS patients who use recreational drugs including alcohol. These studies show that ETOH at concentrations associated with intoxication in vivo can suppress host immune responses to HIV antigens in vitro. This observation may have implications in vivo and may, in part, explain the reduced immunological response often manifested by HIV-infected patients (16) as well as murine AIDS models associated with alcohol ingestion $(26,27,40)$.

\section{ACKNOWLEDGEMENTS}

This work was supported, in part, by NIH grants 1 P50 AA07378, RO1 CA 35922, and 1 RO1 MH47225. We wish to express our appreciation to Ann Sweet for her technical help and Carol Sperry and Gerry Sobkowiak for their excellent secretarial assistance.

\section{REFERENCES}

1. Abdallah, R. M.; Starkey, J. R.; Meadows, G. G. Alcohol and related dietary effects on nouse natural killer cell activity. Immunology 50:131-137; 1983

2. Bagasra, O.; Balla, A. K.; Lischner, H. W. Effects of alcohol ingestion on in vitro susceptibility of peripheral blood mononuclear cells to infection with HIV and of selected T cell functions. Alcohol. Clin. Exp. Res. 13:636-643; 1989.

3. Boyum, A. Isolation of mononuclear cells and granulocytes from human blood. Isolation of mononuclear cells by one centrifugation and of granulocytes by combining centrifugation and sedimentation. Clin. Lab. Invest. 21(Suppl. 97):77; 1968.

4. Centers for Disease Control. Classification systems for human $T$ lymphotropic virus type III lymphadenopathy associated virus infections. MMWR 35:334; 1986.

5. Certa, U.; Rannworth, W.; Stuber, Î.; Gentz, R.; Lanzer, M. S.; LeGrice, S.; Guillot, F.; Wendler, I.; Hunsmann, G.; Bujard, H.; Mous, J. Subregions of a conserved part of the HIV gp 41 transmembrane are differentially recognized by antibodies of infected individuals. EMBO J. 5:3051-3056; 1986.

6. Chang, M. P.; Norman, D. C.; Makinuden, T. Immunotoxicity of alcohol in young and old mice. I. In vitro suppressive effects of ethanol on the activities of $T$ and $B$ cells of aging mice. Alcohol. Clin. Exp. Res. 14:210-215; 1990.

7. Charpentier, B.; Franco, D.; Paci, L.; Charra, M.; Martin, B.; Friss, V. D. Deficient natural killer cell activity in alcoholic cirrhosis. Clin. Exp. Immunol. 58:107-115; 1990.

8. Crowl, R.; Ganguly, K.; Gordon, M.; Conroy, R.; Schaber, M.; Corney, R.; Kramer, R.; Shaw, G. HTLV-III env gene products synthesized in $E$. coli are recognized by antibodies present in the sera of AIDS patients. Cell 41:979-986; 1985.

9. Delacroix, D. L.; Elkon, K. B.; Genbel, A. R.; Hedgson, H. F.; Dive, C.; Verman, J. F. Changes in size, subclass and metabolic properties of serum immunoglobulin $\mathbf{A}$ in liver diseases and in other diseases with high serum immunoglobulin A. J. Clin. Invest. $71: 358-367 ; 1982$.

10. Drew, P. A.; Clifton, P. M.; Labrooy, J. T.; Shearman, D. J. C. Polyclonal B cell activation in alcoholic patients with no evidence of liver dysfunction. Clin. Exp. Immunol. 51:479-486; 1984.

11. Ericsson, D. C.; Kohl, S.; Pickering, L. K.; Davis, G. S.; Faillace, L. A. Mechanisms of host defense in well nourished patients with chronic alcoholism. Alcoholism 4:261-265; 1980.

12. Hodgson, H. J. F.; Wands, J. R.; Isselbaeber, K. J. Alteration in suppressor cell activity in chronic active hepatitis. Proc. Natl. Acad. Sci. U. S. A. 75:1549-1553; 1978.

13. Jerrells, T. R.; Peritt, D.; Marietta, C.; Eckardt, M. J. Mechanisms of suppression of cellular immunity induced by ethanol Alcohol. Clin. Exp. Res. 13:490-493; 1989.

14. Jerrells, T. R.; Smith, W.; Eckardt, M. J. Murine model of etha- nol-induced immunosuppresion. Alcohol. Clin. Exp. Res. 14: $546-550 ; 1990$.

15. Kawanishi, H.; Tavassolie, H.; MacDermott, R. P.; Sheagren, J. $N$. Impaired concanavalin-A inducible suppressor $T$ cell activity in active alcoholic disease. Gastroenterology 80:510-517; 1981.

16. Lake-Bakaar, G.; Rao, R. S. Abstract \#D725 presented at the 5th International Conference on AIDS. Montreal; 1989.

17. MacGregor, R. R. Alcohol and drugs as cofactors for AIDS. Adv. Alcohol Subst. Abuse 7:47-71; 1987.

18. McKeever, Y.; Mahony, C. O.; Whelan, C. A.; Weir, D. G.; Feighery, C. Helper and suppressor $\mathrm{T}$ lymphocyte function in severe alcoholic liver disease. Clin. Exp. Immunol. 60:39-48; 1988.

19. Meadows, G. G.; Blank, S. E.; Duncan, D. D. Influence of ethanol consumption on natural killer cell activity in mice. Alcohol. Clin. Exp. Res. 13:476-479; 1989.

20. Meadows, G. G.; Wallendal, W.; Kosngi, A.; Weinderlich, J.; Singer, D. S. Ethanol induced marked changes in lymphocyte populations and natural killer cell activity in mice. Alcohol. Clin. Exp. Res. 16:474-479; 1992.

21. Momiatis, T.; Fritsch, E. F.; Sambrook, J. Molecular cloning: A laboratory manual. Cold Spring Harbor, NY: Cold Spring Harbor Laboratory; 1982.

22. Morgan, M. Y.; Ross, M. G.; Ng, C. M.; Adams, D. M.; Thomas, H. C.; Sherlock, S. HLA-B8, immunoglobuins and antibody responses in alcohol related liver diseases. J. Clin. Pathol. 33:488-492; 1980.

23. Nair, M. P. N.; Kronfol, Z. A.; Schwartz, S. A. Effect of alcohol and nicotine on cytotoxic responses of human lymphocytes. Clin. Immunol. Immunopathol. 54:395-409; 1990.

24. Nair, M. P. N.; Pottathil, R.; Heimer, E. P.; Schwartz, S. A. Immunoregulatory activities of human immunodeficiency virus (HIV) proteins. Effect of HIV recombinant and synthetic peptides on immunoglobulins. Synthetic and proliferative resoponses by normal lymphocytes. Proc. Natl. Acad. Sci. U. S. A. 85:6498$6502 ; 1988$

25. Nair, M. P. N.; Schwartz, S. A.; Kronfol, Z. A.; Heimer, E. P.; Pottathil, R. Immunoregulatory activities of human immunodeficiency virus (HIV) proteins. Inhibitory effect on natural killer (NK) cell functions. Abstract presented at the 7th International Congress of Immunology. Berlin; 1989.

26. Nelson, S.; Bagby, G. J.; Summer, W. R. Alcohol induced suppression of INF-alpha, potential risk factor for secondary infection in the AIDS progress. Clin. Biol. Res. 325:211-220; 1990.

27. Pillai, R. M.; Watson, R. R. Disease progression and immunodulation by drugs of abuse and alcohol. AIDS Med. Report 4:2536; 1991 .

28. Pollack, E. S.; Nomura, A. M.; Heilburn, L. K.; Stemmermann, 
G. N.; Green, S. B. Prospective study of alcohol consumption and cancer. N. Engl. J. Med. 310:617-621; 1984.

29. Pottathil, R.; Crowl, R. M.; Heimer, E. P.; Mous, J. Recombinant antigens and synthetic peptides as diagnostic agents for detection of human immunodeficiency virus infection. Med. Virol. 7:225-243; 1988.

30. Rook, A. H.; Masur, H.; Lane, H. C.; Frederik, W.; Kasahara, T.; Macher, A. M.; Djeu, J. Y.; Manischewitz, J. F.; Jackson, L.; Fauci, A. S.; Quinnan, G. V. Interleukin-2 enhances the depressed natural killer and cytomegalovirus-specific cytotoxic activities of lymphocytes from patients with the acquired immune deficiency sydrome. J. Clin. Invest. 72:398-403; 1983.

31. Roselle, G. A.; Mendenhall, C. L.; Grossman, C. J. Ethanol and soluble mediators of host response. Alcohol. Clin. Exp. Res. 13: 494-498; 1989.

32. Rosenberg, Z. F.; Fauci, A. S. Immunopathogenic mechanisms of HIV infection. Clin. Immunol. Immunopathol. 50:5149-5156; 1989.

33. Saxena, Q. B.; Nezey, E.; Adler, W. H. Regulation of natural killer activity in vivo. II. The effect of alcohol consumption on human peripheral blood natural killer cell activity. Int. J. Cancer 26:413-417; 1980 .

34. Shoeman, R. L.; Young, D.; Pottahil, R.; Victor, J.; Conroy,
R. R.; Crowl, R. M.; Coleman, T.; Heimer, E.; Lai, C. Y. Ganguly, L. Comparison of recombinant human immunodeficiency cirus gag precursor and gag/env fusion progeins and a synthetic env peptide as diagnostic reagents. Anal. Biochem. 161: $370-379 ; 1987$.

35. Siegal, L. AIDS, relationship to alcohol and other drugs. J. Subst. Abuse Treat. 3:271-274; 1986.

36. Stacey, N. H. Inhibition of antibody dependent cell mediated cytotoxciity by ethanol. Immunopharmacology 8:155-161;1984.

37. Stall, R. The prevention of HIV infection associated with drug and alcohol use during sexual activity. Adv. Alcohol Abuse 7:73$89 ; 1987$.

38. Stimmel, B. AIDS, alcohol and heroin: A particularly deadly combination. Adv. Alcohol Subst. Abuse $6: 1-5 ; 1987$.

39. Watson, R. R.; Eskelson, C.; Hartman, B. R. Severe alcohol abuse and cellular immune function. Arizona Med. 10:665-668; 1984.

40. Watson, R. R.; Probhala, R. H.; Darban, H. R.; Tahya, M. D.; Smith, T. L. Changes in lymphocyte and monophages subset due to morphin and extranol treatment during retrovirus infection causing murine AIDS. Life Sci. 43:V-XI; 1988.

41. Woltjen, J. A.; Zelterman, R. K. Suppressor cell activity in primary biliary cirrhosis. Dig. Dis. Sci. 25:104-107; 1980. 